\title{
과제지향적 다양한 운동학습(다트던지기)이 교유감각에 미치는 영향
}

\author{
양병일', 박형기 ${ }^{* 2}$ \\ ${ }^{1}$ 수원요양병원 물리치료실, ${ }^{2}$ 마산대학교 물리치료과
}

\author{
Task-Oriented Effects of Various Exercise Learning (Dart Throwing) on Proprioception \\ Byung-Il Yang ${ }^{1}$, Hyeong-Ki Park ${ }^{* 2}$ \\ ${ }^{1}$ Department of Physical therapy, Suwon Convalescent Hospital \\ ${ }^{* 2}$ Department of Physical Therapy, Masan University
}

Purpose In this study, 45 students were divided into task - oriented group, task - oriented intermittent group, and continuous group, and the effect of each variable on learning was changed to angle of the arms' we checked. Methods This study was conducted for 45 days from March 13 to 18, 2017 for five days in the 20 generals living in Changwon city. Dart and goniometer were used for the measurement. In the exercise program, darts were placed on a smooth, hard surface of $1.5 \mathrm{M}$ height and the distance to the subject was set $1.5 \mathrm{~m}$ away. In the dart throw practice, all three groups were marked with an elbow flexion $30^{\circ}$ on the wall, and the subjects were instructed to throw the dart at that point. Results Comparisons between groups showed significant differences between the continuous task-oriented training group and the intermittent task-oriented training group and the control group at the end of training $(* * * \mathrm{P}<0.001)$. Conclusion This study showed that the intermittent task-oriented training method showed the highest effect $(* * * \quad \mathrm{P}<0.001)$, which proved that the intermittent method is the most effective exercise method among the three groups.

Key words Task oriented group, Task - oriented intermittent group, Dart throwing, Proprioception, Feedback.

Corresponding author Hyeong-Ki Park(simile70@naver.com)

Received date 20 September 2018

Revised date 06 October 2018

Accepted date 08 October 2018

\section{I. 서 론}

뇌졸중과 같은 중추신경 손상 환자의 기능적 회복은 의료적 손상을 해결할 뿐만 아니라 육체적, 감각기능, 지각능력 및 인 지능력과 심리사회적 잔여 기능장애를 치료하는 과정이다. 뇌 손상으로부터 회복과정은 기능을 상실한 후 새로운 기능을 습 득하는 학습과정이라고 할 수 있다. 일상생활들을 재교육하는 중추신경계 환자는 일상생활에서 최대한의 기능적 독립을 필 요로 한다. 숙련된 일상생활을 성취하기 위해서는 운동학습이 필요하며, 운동학습은 숙련된 수행에 필요한 능력을 지속적이 며 영구적으로 변화시키는 연습과 경험의 과정이다. ${ }^{1)}$ 중추신 경 손상 환자를 치료하는 물리치료사는 환자의 기능적인 능력 들을 재학습 시키기 위해 치료적인 틀에 운동학습 원리를 이 용 할 수 있다. 일반적으로 중추신경 손상 환자의 운동학습은 새로운 기술을 습득하기 보다는 환자의 기존 학습된 잠재된 기술습득을 이끌어 내어 적용해야 한다고 강조하였다. ${ }^{1-2)}$

http:dx.doi.org/10.17817/2018.10.06.111311
이러한 기술습득에는 되먹임(feedback)이 중요하다. 중추 신경 손상환자들에 있어서 되먹임은 운동학습의 중요한 변수 이다. 일반적으로 재활을 위한 운동학습은 크게 5 가지로 나눌 수 있는데 첫 번째는 집중연습과 분산연습(distributed practice)이 있다. 집중연습은 운동학습 시 치료시간이 휴식시간보 다 시간할당이 긴 경우를 의미하고 분산연습은 학습을 시행 시 상당시간 휴식시간이 치료시간보다 긴 경우를 의미한다. 분산연습은 선행 연구에 따르면 수행과 학습에 모두 긍정적인 효과를 나타냈으나 환자가 더 많은 양의 훈련을 하기 원한다 면 집중연습을 계획하되 운동학습 프로그램 설계 시 충분한 휴식 시간을 통해 과도한 피로를 유발시키지 않도록 해야 한 다고 보고되고 있다. ${ }^{3)}$ 두 번째로 운동학습에 있어 중요한 변 수는 불변연습(constant practice)과 가변연습(variable practice)이 있다. 운동학습에 있어 한 가지 방법으로만 지속적으 로 연습을 하는 불변연습과 여러 가지 방법을 순서에 상관없 이 무작위하게 뒤섞어 연습하는 가변연습이 있다. 선행연구의 보고에 의하면 불변연습보다는 가변연습 집단에서 새로운 과 제를 학습 시 결과적으로 운동학습을 더 잘 수행하였다고 보 
고하였다. ${ }^{4)}$ 세 번째 운동학습 방법에 있어 중요한 변수 중 하 나는 전체연습(whole training)과 부분연습이(part training) 있다. 운동학습에 있어 새로운 과제를 환자에게 적용 시 환자 가 과제전체를 학습하는 방법을 전체연습이라 하고 과제를 여 러 단계로 나누어 각각의 단계를 학습하는 방법을 부분연습이 라 한다. 부분연습은 환자에게 과제를 수행 시 과제와 각 단 계의 난이도별 연결능력이 낮을 경우 부분연습을 수행해야 한 다. 반대로 과제와 각 단계별 상호의존성이 높지만, 과제의 단 계가 많지 않거나 주의 집중을 많이 요구하지 않는다면 전체 연습을 선택하는 것이 효과적이다. 마지막으로 네 번째는 구 획연습(blocked training)과 무작위연습(random practice) 이 있다. 구획연습이란 순서에 따라 과제를 시행하는 것으로 과제 $\mathrm{A}$ 에 대한 모든 수행을 마친 후 과제 $\mathrm{B}$ 를 수행하고 과제 $\mathrm{C}$ 로 순차적으로 전환하는 방법이다. 구획연습에서는 다음 과 제로 넘어가기 전에 그 때에 주어진 모든 과제의 수행을 완료 해야 한다.

마지막으로 운동학습에 있어 또 다른 방법은 무작위연습 (Random practice)인데 무작위 연습방법은 훈련과제 $\mathrm{A}, \mathrm{B}$, $\mathrm{C}$ 의 연습의 수행이 임의대로 서로 무작위로 학습시키는 방법 으로 이것은 어떤 과제도 두 번의 연속적 시도로 반복되지 않 도록 하기 위한 방법이다. 과제지향적 모델(task-oriented model)은 중추 신경손상 환자들을 위한 재활치료에 활발히 적용이 되고 있으며 현재는 중추신경 재활뿐만 아니라 다양한 분야에서 또한 운동조절의 개념들을 결합하려 노력하고 있다. 최근 들어 중추신경 재활에서 가장 많은 시간을 할애하는 것 은 운동조절 이론에 입각한 수직계층적, 시스템적 이론과 통 합된 과제지향적 모델까지 신경 손상환자에게서 기능회복을 위한 다양한 시도를 시행하고 있다. 이런 다양한 운동학습은 움직임 조절이 환경과 연관하여 목표 지향적인(goal-directed) 과제훈련과 병행하여 수행 시 일상생활 동작의 의미 있는 회복을 얻을 수 있다고 보고되고 있다. 2000년대 들어 신경 손상 환자의 재활에 있어 과제를 이용한 과제지향적 다 양한 운동학습이 같은 과제라도 목표에 따라 매우 다양한 움 직임 패턴들이 나타나며 효과적으로 성취될 수 있기 때문에 재활치료실 내에서 치료사들은 하나의 정형적인 획일화된 정 상 움직임 패턴만을 학습시키도록 제한하지 않고 환자가 가능 한 한 효과적으로 운동학습을 협응하기 위해 새로운 운동전략 을 세우는 것이 중요하다. 현재 근거에 입각한 임상에서 재활 훈련 시 점차적으로 운동학습을 배우고 기능적인 인체동작을 갖추는 학습 수단으로 과제지향적 운동과 운동훈련에 중점을 두고 있다. Liepert 등(2001)의 보고에 따르면 운동학습과 대 뇌피질 재구성에 집중적이고 반복적인 과제지향적 운동과 다 양한 훈련을 병행하였을 때 가장 이상적인 운동학습 수행능력 이 나타난다고 보고하였다. ${ }^{5)}$
이에 본 연구에서는 정상인에게 있어서 과제지향적 다양한 운동학습 중 간헐적인 방법과 지속적인 방법에 의한 운동학습 이 고유 감각에 어떠한 영향을 미치는지 알아보고 어떠한 상 관성이 있는지 알아보고자 하는 것이다.

\section{II. 연구 방법}

\section{1. 연구대상 및 기간}

본 연구는 경상남도 창원시에 소재한 $\mathrm{M}$ 대학교 재학중인 20 대 대학생 45명을 대상자로 선정하였다. 본 연구는 2017년 3 월 13일부터 18일까지 5일 동안 실시하였으며 대상자는 독립 적인 일상생활이 가능한 일반인 중에 지시에 따라 행동할 수 있고 스스로 일어설 수 있으며 외부의 보조 없이 보행이 가능 한 자로 선정하였다.

본 연구의 대상자중 다음에 해당하는 하는 자는 제외 하였다.

가. 중추 또는 말초 신경에 병변이 있는 자.

나. 완전 시각. 청각 장애인.

다. 최근에 정형외과적 문제가 있는 자.

\section{2. 연구절차 및 방법}

본 연구는 다양한 운동학습이 대상자들의 고유감각에 미치는 영향을 알아보기 위하여 간헐적 방법과 지속적 방법 그리고 과제지향적 방법을 적용하였다. 학습방법에 따른 차이를 알아 보기 위한 측정도구는 다트와 Goniometer를 사용하였다.

본 연구는 대상자로부터 사전에 충분한 실험에 대한 설명 을 통하여 이해를 하고 자발적 실험에 동의한다는 동의서를 받고 본 연구를 시행하였다. 본 연구는 20 대 대학생 남,여 45 명의 대상자를 무작위로 선정하여 세 그룹으로 나누어 연구에 참여하였다.

본 연구 운동 프로그램은 지속적인 방법의 과제지향적 $\mathrm{A}$ 집단, 간헐적인 방법의 과제지향적 $\mathrm{B}$ 집단, 대조군 $\mathrm{C}$ 집단으 로 무작위 추출한 세 그룹으로 구분하여 진행하였다.

본 연구의 운동프로그램은 다트를 $1.5 \mathrm{M}$ 높이의 매끄럽고 딱딱한 표면에 설치하였고, 대상자와의 거리는 $1.5 \mathrm{M}$ 떨어지게 설치하였다. 다트 던지기 연습은 3그룹 모두 벽에 elbow flexion $30^{\circ}$ 되는 지점을 표시해 놓고 대상자가 다트를 그 지 점에서 던지도록 지시하였다. 과제지향 지속적인 방법의 실험 군 $\mathrm{A}$ 는 훈련기간 총 6일 중 다트 던지기를 3일 동안 매일 실 시하고 3일 휴식을 취하는 방법으로, 1 번에 20회씩 던지고 2 분 휴식하는 과정을 3 번 반복하여 총 60 회 실시하였다. 과제지 향 간헐적인 방법의 실험군 $\mathrm{B}$ 는 6 일 동안 실험과 휴식을 격일 로 매일 60회씩 과제지향 지속적 방법의 실험군과 같이 실험 을 실시하였다. 대조군 C 그룹은 평가 전, 후 만 측정하였다. 


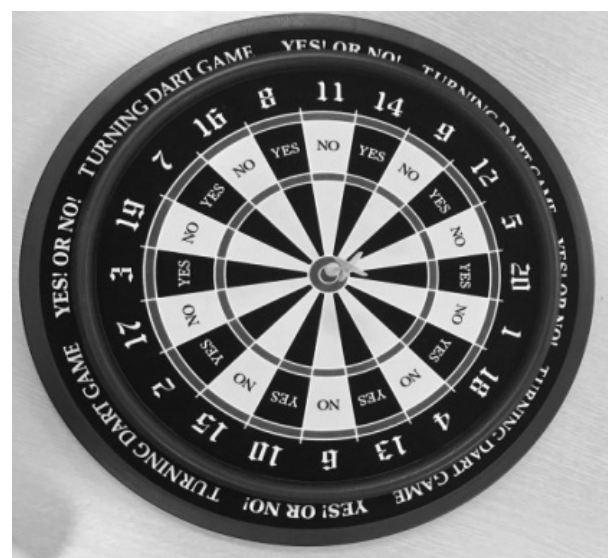

Figure1. Dart

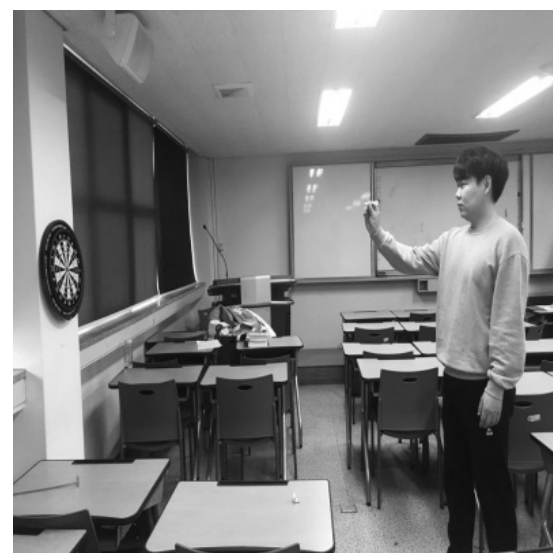

Figure3. Dart throwing training

고유감각 측정은 연구 종료 마지막 날 $\mathrm{A}$ 그룹과 $\mathrm{B}$ 그룹 그 리고 대조군 $\mathrm{C}$ 그룹 모두 시각을 차단시킨 후 팔꿉관절 굽힘 $30^{\circ}$ 되는 지점을 다트를 던질 때 그 지점에서 팔을 멈추는 것 으로 측정하였다. 실험군 $\mathrm{C}$ 는 사전에 $30^{\circ}$ 라는 각도만 인지시 키고 연습은 하지 않고 측정하였다. 모든 점수는 던지는 동작 시 팔꿉관절 굽힘 $30^{\circ}$ 에서 벗어나는 오차를 계산하였다.

\section{3. 분석 방법}

본 연구를 통하여 얻어진 결과는 조사된 각 항목을 수치화 한 후, 자료의 통계 처리는 상용통계 프로그램인 윈도우즈용 SPSS version 18.0.0을 사용 하였다. 집단 간 고유 감각의 차이를 알아보기 위하여 일요인 분산분석(one-way ANOVA)

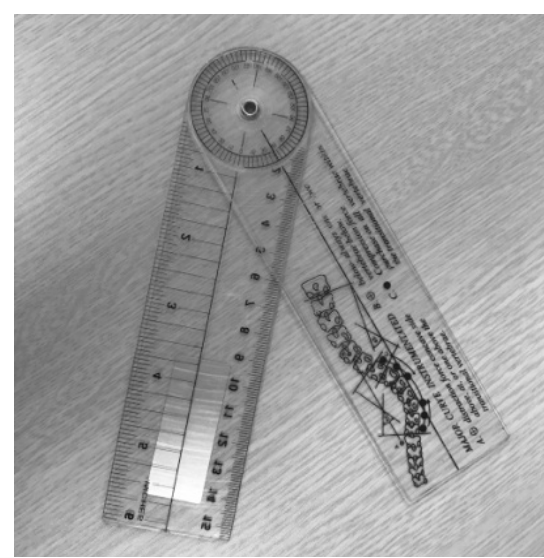

Figure2. Goniometer

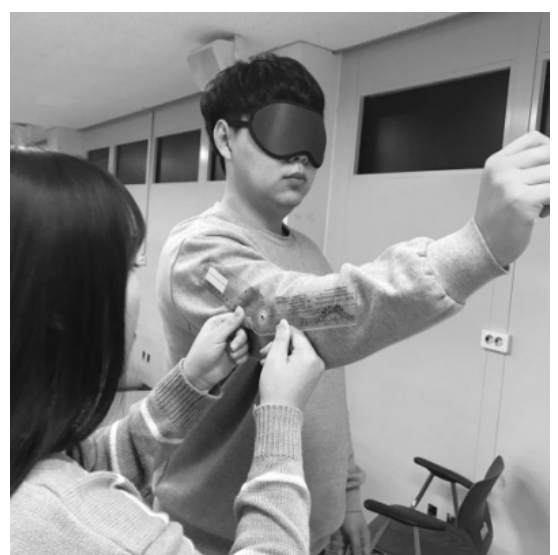

Figure3. EEG measurement at imagine training

을 사용하였고, 집단 내 연습 전, 후의 고유감각의 차이를 알 아보고 자 paired t-test를 사용하였다. 모든 통계학적 유의수 준은 $\mathrm{a}=0.05$ 로 하였다.

\section{III. 결 과}

\section{1. 대상자의 일반적 특성}

일반적인 연구대상자는 20 대 대학생 45 명을 대상으로 하였다. 그룹은 지속적인 과제지향적 그룹 15 명과 간헐적 과제지향적 그룹 15 명, 훈련을 하지 않은 대조군 15 명으로 총 3 그룹으로 나누어서 연구를 진행하였다. 대상자의 그룹간 일반적 특성은 다음과 같다(표 1).

Table 1. General characteristics of the subjects $(N=30)$

\begin{tabular}{cccc} 
Group & Age & Height (cm) & Weight (kg) \\
Task-oriented constant practice $(\mathrm{N}=15)$ & $22.57 \pm 1.72$ & $165.43 \pm 3.74$ & $53.86 \pm 8.55$ \\
Task-oriented variable practice $(\mathrm{N}=15)$ & $20.42 \pm 2.04$ & $171.43 \pm 7.81$ & $59.71 \pm 12.7$ \\
Control $(\mathrm{N}=15)$ & $20.43 \pm 2.57$ & $174.14 \pm 5.87$ & $66.00 \pm 15.15$ \\
\hline
\end{tabular}


본 연구결과 팔꿉관절 굽힘 $30^{\circ}$ 에서 다트 던지기를 통한 고 유감각 증진 훈련을 시행한 결과 지속적 과제지향적 훈련을 시행한 집단에서는 관절 각도 $20.47^{\circ}$ 에서 $23.87^{\circ}$ 로 정확도가 증진되었으며 $(* * p<0.01)$, 간헐적 과제지향적 훈련을 시행한 집단에서는 $21.13^{\circ}$ 에서 $28.00^{\circ}$ 로 정확도가 증진되어 통계학 적으로 유의한 차이를 보였다(*** $\mathrm{P}<0.001)$. 또한 대조군 집단 에서도 $21.20^{\circ}$ 에서 $22.53^{\circ}$ 로 증가하였으나 통계학적으로는 연구 전, 후 유의하지 않았다(표2). 집단 간 비교에서는 훈련 이 종료된 시점에서 지속적 과제지향적 훈련집단과 간헐적 과 제지향적 훈련집단 및 대조군 집단간에 유의한 차이를 보였다 $\left.{ }^{(* * *} \mathrm{P}<0.001\right)($ 표3).

\section{IV. 고 찰}

본 연구는 운동학습의 종류 중 과제지향적 다양한 운동학습이 고유감각에 미치는 영향에 대해 알아보고 자 45 명의 학생을 대상으로 과제지향적 지속집단, 과제지향적 간헐적 집단과 대 조군으로 나누어 각 변인이 고유감각에 미치는 영향을 다트를 던질 시 팔꿉관절의 각도를 통해 변화를 평가하였다. 최근 운 동학습에서 과제를 이용한 과제지향적 훈련방법이 중추신경 손상 환자들의 재활훈련에 있어 중요한 학습 방법으로 연구되 고 있으며 치료실 내에서 적용이 되고 있다. 이러한 과제지향 적 훈련은 일상생활 중 일어나는 기능적 움직임에 밀접한 연 관성이 있으며 기능적 움직임의 학습은 중추신경 감각 및 운 동 시스템의 통합과 여러 관절의 협응 및 효율적 선택적 움직 임의 향상을 의미한다. ${ }^{口}$

본 연구에서 과제를 이용한 다양한 학습방법을 집단화 설
계한 이유는 과제를 통한 동기부여를 제공하기 위해서다. 동 기부여에서 동기란 말은 움직인다(move)는 단어에서 파생되 었으며, 동기는 움직임(movement)을 가져오는 과정이며, 이 움직임은 행동을 일으키는 방향설정에 중요한 계기가 된다.

과제 지향적 훈련은 구체화된 운동과제를 제시함에 따라 동기부여를 일으키며 과제해결을 위한 다양한 관절 참여와 속 도 및 방향을 중재함으로 민첩성, 고유감각 증진, 근력운동 및 수축 타이밍과 강도를 제공함으로 인지적이고 흥미를 유발하 는 훈련방법이다. ${ }^{7-8)}$ 이러한 과제훈련 방법은 다양한 운동학습 방법에 따라 다르게 제공되는데 본 연구는 과제를 재활에 참 여시 지속적인 운동학습과 간헐적 과제 훈련 중 어떠한 과제 훈련이 운동학습에 더 나은 중재 방법임을 알아보고 자 하였 다. 본 연구 결과 다트던지기를 매일 블록화 된 방법으로 훈 련하는 지속적 과제훈련 방법과 간헐적 과제훈련 간헐적 훈련 방법이 더 나은 연구 결과를 나타내었다 $(* * * 0<0.001)$. 이는 선행연구에서 뇌성마비 아동의 선 자세 능력 균형훈련 과제를 시행하였을 때 간헐적인 적용방법이 지속적인 시각적 되먹임 의 적용방법보다 더 효과적일 수 있다는 연구 결과를 지지한 다. ${ }^{9-10)}$ Schmidt 등(1991)의 보고에 의하면 운동학습에 최대 효과를 이루기 위해선 다양한 훈련을 무작위순으로 연습을 시 행 하였을 시 최대 학습효과를 얻을 수 있다고 보고하였다. ${ }^{1)}$

본 연구결과 또한 고유감각을 증진 시키기 위한 감각적 피 드백 제공을 간헐적으로 무작위순으로 연습을 시행하였을 가 장 운동학습 효과가 극대화 되는 것을 확인 할 수 있었 다. ${ }^{11-12)}$ 향우 이러한 연구결과를 토대로 좀 더 다양한 연구가 필요할 것으로 사료된다. 향후 젊은 대상자가 아닌 노인 남,여 를 대상으로나 정상인이 아닌 인지기능이 문제가 없는 중추신 경계 환자들에게 치료적 목적으로 간헐적 과제훈련을 적용하

Table 2. A comparison of proprioception ability between pre-post value for the three groups

\begin{tabular}{cccccc}
\hline & Pre-test & Post-test & t & p \\
Task-oriented constant practice $(\mathrm{N}=15)$ & $20.47 \pm 2.26$ & $23.87 \pm 4.66$ & -3.340 & $.005^{* *}$ \\
Task-oriented variable practice $(\mathrm{N}=15)$ & $21.13 \pm 2.37$ & $28.00 \pm 4.67$ & -9.499 & $.000^{* * * *}$ \\
Control $(\mathrm{N}=15)$ & $21.20 \pm 1.66$ & $22.53 \pm 2.67$ & -1.919 & .076 \\
\hline
\end{tabular}

${ }^{*} \mathrm{P}<0.05,{ }^{* *} \mathrm{p}<0.01,{ }^{* * *} \mathrm{P}<0.001$

Table 3. Difference of inter-group exercise learning by three exercise methods

(unit:degree)

\begin{tabular}{cccccc} 
& $\begin{array}{c}\text { Task-oriented constant } \\
\text { practice }(\mathrm{N}=15)\end{array}$ & $\begin{array}{c}\text { Task-oriented variable } \\
\text { practice( } \mathbf{N}=15)\end{array}$ & Control(N=15) & p \\
Pre-test & $20.47 \pm 2.26$ & $21.13 \pm 2.37$ & $21.20 \pm 1.66$ & .546 \\
Post-test & $23.87 \pm 4.66$ & $28.00 \pm 4.67$ & $22.53 \pm 2.67$ & 11.044 & $.000^{* * * *}$ \\
\hline
\end{tabular}

${ }^{*} P<0.05,{ }^{* *} \mathrm{p}<0.01,{ }^{* * *} \mathrm{P}<0.001$ 
여 좀 더 효율적인 운동학습 방법을 연구할 필요가 있다고 생 각된다. 본 연구의 제한점으로는 다양한 연령대가 참여하지 않았으며 운동학습 기간이 짧아 일반화 하기 어렵다. 또한 본 연구는 단순한 감각되먹임 제공으로 다트던지기 과제훈련을 시해하였기에 좀 더 다양한 과제를 통한 감각되먹임 제공 시 어떠한 효과가 있는지 확인 할 필요가 있을 것으로 사료된다.

본 연구는 다트던지기 과제를 통한 과제지향적 간헐방법과 과제지향적 지속방법 중 어떠한 운동학습 방법이 고유감각에 긍정적 효과를 미치는 지 알아보고 자 창원에 소재한 $\mathrm{M}$ 대학 교에서 성인 남녀 45 명을 대상으로 연구를 실시하였다. 본 연 구결과 간헐적 과제지향적 훈련방법에서 가장 높은 효과가 나 타났으며 $\left.{ }^{* * *} \mathrm{P}<0.001\right)$ 이는 간헐적 방법이 세집단 간 운동학 습 방법 중 가장 효과적인 운동방법임을 입증하였다. 향후 더 욱 많은 대상자를 대상으로 우세 손, 비우세 손 및 성별, 다양 한 연령대 별, 질환 별 과제를 통한 다양한 운동학습 방법을 연구하여 임상활용에 기초적 자료로 활용하기를 기대한다.

\section{References}

1. Schmidt RA, Young DE. Augmented kinematic information feedback for skill learning: A new research paradigm. Journal of Motor Behavior. 1991;23(1):13-24.

2. Winsten CJ. Relative Frequency of information Feedback in Motor Performance and Learning. Los Angeles. University of California, Los Angeles; 1988.

3. Lee TD, Genovese ED. Distribution of practice in motor skill: learning and performance effects reconsidered. 1988;59:59-67.

4. Schmidt RA, Lee TD. Motor control and learning: a behavioral emphasis, Champaign, IL: Human Kinetics, 2005 .
5. Liepert J, Bauder H, Wolfgang HR, et al. Treatmentinduced cortical reorganization after stroke in humans. Stroke. 2000;31(6):1210-1216.

6. Carr JH, Shepherd RB. Neurological Rehabilitation: Optimizing Motor Performance. Oxford, United Kingdom:Butterworth-Heinemann Ltd; 1998.

7. Vearrier LA, Langan J, Shumway-Cook A et al. An intensive massed practice approach to retraining balance poststroke. Gait Posture. 2005;22:154-63.

8. Johnson MJ, Feng X, Johnson LM, Winters JM. Potential of a suite of robot computer assisted motivating systems for personalized, home-based, stroke rehabilitation. J Neuroeng Rehabil. 2007;4:6.

9. Seo HJ, Kim S, Kwon HC et al. The Effect of Intermittent and Continuous Visual and Auditory Feedback at Standing Balance Training in Children with Cerebral Palsy. Korean Research Society of Physical Therapy. 2009;7(3):62-1.

10. Emken JL, Reinkensmeyer DJ. Robot enhanced motor learning: accelerating internal model formation during locomotion by transient dynamic amplification. IEEE Trans Neural Syst Rehabil Eng. 2005;13:33-39.

11. Park JM, Lee SH. The effect of knee joint position sense through close and open kinetic chain exercise on the proprioception and balance ability of elderly people. The Journal of Korean Society for Neurotherapy. 2018;22(3):27-32

12. Yang BI, Hwang BY. Effects of knee extensor muscle fatigue of chronic patients in the balance. The Journal of Korean Society for Neurotherapy. 2014;18(1):37-44. 